\title{
Prediction of Gingival Recession after Flap Surgery in Patients with Chronic and Aggressive Periodontitis with Horizontal or Vertical Bone Loss
}

\author{
Shivaprasad Bilichodmath ${ }^{1}$, Geetha K. ${ }^{2}$, Sayana Nazrine ${ }^{3}$, Nimmi Janardhanan ${ }^{4}$ \\ 1,2,3,4 Department of Periodontology, Rajarajeswari Dental College and Hospital, Bengaluru, Karnataka, India.
}

\section{ABSTRACT}

\section{BACKGROUND}

The sites with deeper periodontal pockets showed greater postoperative gingival recession. The purpose of this study was to correlate the gingival recession following the periodontal flap surgery with the amount of bone loss at the treated site and to propose a prediction chart of post -operative gingival recession based on certain clinical parameters.

\section{METHODS}

A total of 120 sites in patients with chronic and aggressive periodontitis were treated with flap surgery. Clinical parameters such as probing pocket depth (PPD), recession depth (RD) and clinical attachment level (CAL) were recorded at baseline, 1 month, 3 months and 6 months post-surgery. The extent of bone loss in the surgical site was measured in digital radiographs (RVG) at baseline. The prediction chart for post-operative recession depth was prop osed based on the amount of bone loss in surgical site and the clinical parameters.

\section{RESULTS}

The difference in mean PPD, CAL and gingival recession depth from baseline to 1 month, 3 month and 6 months was statistically significant. Out of 120 sites, 38 sites with the bone loss of 3-5 mm showed increase in gingival recession from baseline $(0.89 \mathrm{~mm} \pm 0.924 \mathrm{~mm})$ to 6 months $(1.47 \mathrm{~mm} \pm 0.979)$ post-surgery. The difference was statistically significant $(\mathrm{p}<0.05)$. The mean gingival recession was increased from baseline ( $1.46 \mathrm{~mm} \pm 1.58 \mathrm{~mm})$ to 1 month $(2.80 \mathrm{~mm} \pm 1.54 \mathrm{~m}), 3$ months (2.93 $\mathrm{mm} \pm 1.465 \mathrm{~mm})$ and 6 months $(2.98 \mathrm{~mm} \pm 1.49 \mathrm{~mm})$ after surgery in 54 sites with the bone loss of 5-10 mm. The difference was statistically significant $(\mathrm{p}<0.001)$.

\section{CONCLUSIONS}

In our study, it was concluded that gingival recession following flap surgery correlates with the bone loss at the surgical site and sites with greater bone loss showed increased postoperative recession.

\section{KEY WORDS}

Chronic Periodontitis, Aggressive Periodontitis, Flap Surgery, Gingival Recession, Bone Loss, Prediction.
Corresponding Author:

Dr. Shivaprasad Bilichodmath, Professor,

Department of Periodontology, Rajarajeswari Dental College and Hospital, No. 14, Ramohalli Cross, Mysore Road, Kumbalgodu, Bengaluru-560074, Karnataka, India.

E-mail:drspbmath@gmail.com

DOI: $10.14260 / j e m d s / 2022 / 37$

How to Cite This Article:

Bilichodmath S, Geetha K, Nazrine S, et al. Prediction of gingival recession after flap surgery in patients with chronic and aggressive periodontitis with horizontal or vertical bone loss. J Evolution Med Dent Sci 2022;11(01):194-198, DOI: $10.14260 /$ jemds $/ 2022 / 37$

Submission 08-12-2021,

Peer Review 20-01-2022,

Acceptance 27-01-2022,

Published 29-01-2022.

Copyright (c) 2022 Shivaprasad Bilichodmath et al. This is an open access article distributed under Creative Commons Attribution License [Attribution 4.0 International (CC BY 4.0)] 


\section{BACKGROUND}

Gingival recession (GR) is the term that describes the exposure of the root surface of teeth due to the migration of gingival margin apical to the cementoenamel junction (CEJ), which can be either localized or generalized.1,2 Recession is a prevalent and unwanted condition of the gingiva and is often accompanied with clinical problems such as plaque retention, root surface hypersensitivity, root caries, cervical root abrasions, erosions, and aesthetic dis-satisfaction. ${ }^{3,4}$

The aetiology of gingival recession consists of various factors such as, improper tooth brushing, tooth malposition, smoking, destructive periodontal disease, alveolar bone dehiscence, occlusal trauma, high muscle attachment, aberrant frenal pull and iatrogenic factors such as prosthetic, orthodontic, restorative and periodontal therapy. ${ }^{5}$

Previous studies found that recession occurred following both nonsurgical and surgical periodontal therapy, which led to various sensitivity and aesthetic problems.6,7 Surgical debridement is a standard procedure to treat deep periodontal pockets in chronic and aggressive periodontitis patients with vertical or horizontal bone loss. Postoperatively, surgical debridement and flap repositioning might result in notable gingival recession. ${ }^{8}$ This postoperative recession was found to correspond with initial probing depth, i.e., it was considerably higher in sites with deeper periodontal pockets. ${ }^{9}$ Several explanations have been suggested for the postoperative recession including the thin gingival tissue with limited blood supply, lack of bone support for the flap, and postoperative shrinkage of the flap. ${ }^{9,10}$

According to our knowledge there are no studies in the literature to correlate the postoperative gingival recession with the amount of bone loss in the surgical site.

Based on the aforementioned findings the purpose of the present study was to correlate the gingival recession following the periodontal flap surgery with the amount of bone loss at the treated site and to propose a prediction chart of post -operative gingival recession based on certain clinical parameters.

\section{METHODS}

A longitudinal study wherein a total of 120 sites in 80 patients with chronic and aggressive periodontitis were randomly selected from the Outpatient Department of Periodontology, Rajarajeswari Dental College and Hospital, Bangalore.

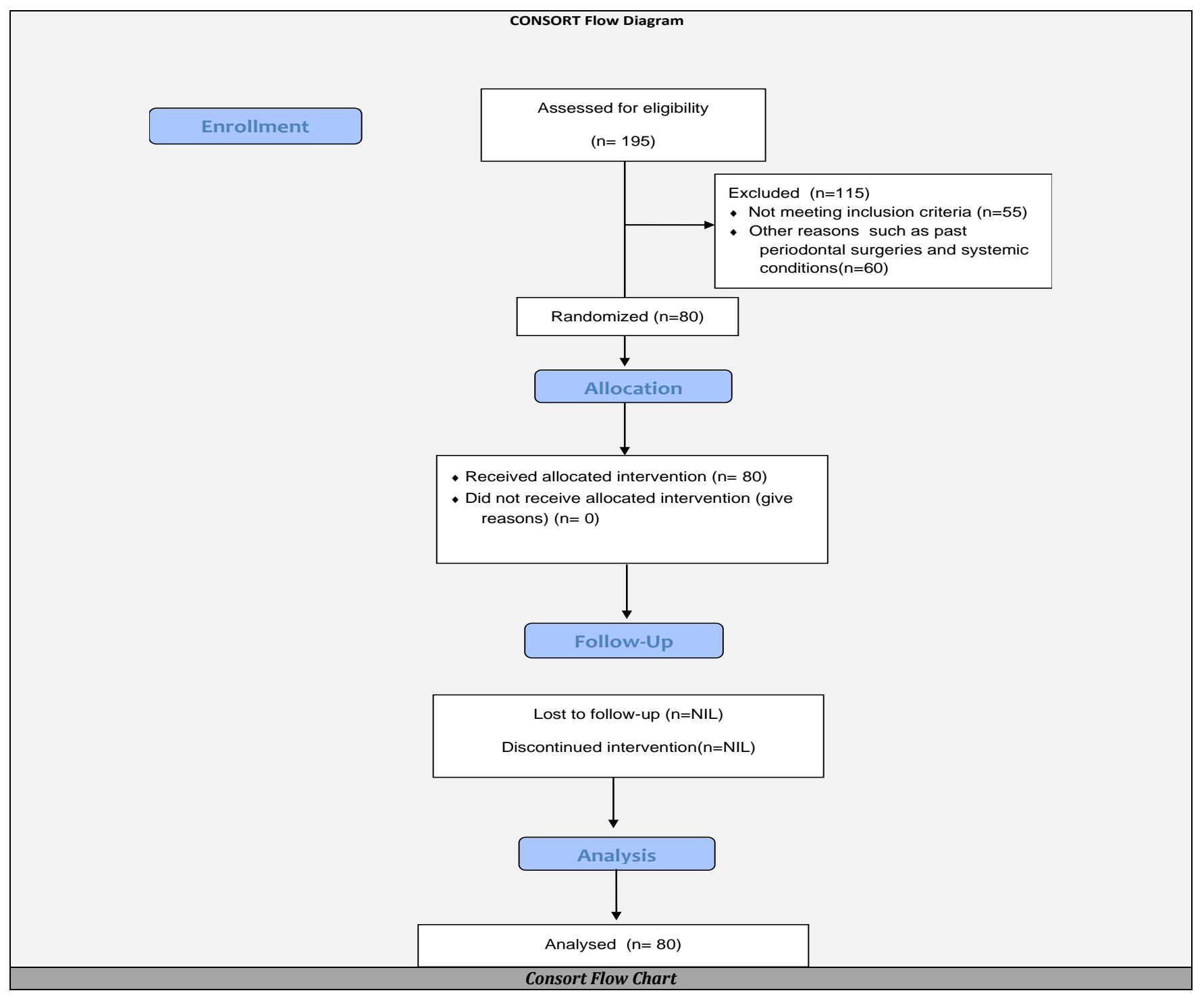


The sample size was estimated using the GPower software v. 3.1.9.4 [Franz Faul, Universität Kiel, Germany]. The research protocol was approved by institutional ethical committee and was registered under Clinical Trials RegistryIndia (CTRI/2018/08/015327-Reg no). This was a clinical study carried out for a period of 6 months (from May 2019 to November 2019). The purpose and procedure of the study was described to patients and an informed consent was obtained.

The chronic and aggressive periodontitis patients with PPD $>6 \mathrm{~mm}, \mathrm{CAL}>3 \mathrm{~mm}$ and gingival recession depth of $<$ $1 \mathrm{~mm}$ with the radiographic horizontal or vertical bone loss, patients in the age group of 25-60years were included in the study.

The patients who had undertaken periodontal treatment in the past six months and those with history of known systemic diseases, smokers, pregnant and lactating women were excluded from the study.

Clinical parameters such as probing pocket depth, recession depth and clinical attachment level were recorded using graduated Williams periodontal probe at baseline, 1month, 3 months and 6 months post-surgery. The extent of bone loss in the surgical site was measured from a fixed reference point (i.e., cemento-enamel junction) to the alveolar crest in digital radiographs (RVG) at baseline. The measurements were made in millimetres with the help of a ruler in the Kodak dental imaging software version 6.12.10.0. The prediction chart for post-operative recession depth was proposed based on the amount of bone loss in the site of surgery and the clinical parameters such as PPD and CAL.

All the clinical parameters were assessed by the single examiner. The periodontal flap surgeries were carried out by the postgraduates under the guidance of an experienced periodontal faculty in the Department of Periodontology, Rajarajeswari Dental College and Hospital. The features of the surgery comprised of the flap being elevated with crevicular incision; no osseous surgery was done. The flap was positioned back without any displacement. All patients received oral hygiene instructions following the procedure.

\section{Statistical Analysis}

The data collected was submitted in Microsoft Excel and statistical analyses were performed using the Statistical Package for Social Science (SPSS version 18.5) software. The comparison between the groups was carried out using non parametric test such as Mann Whitney U test, Kruskal Wallis test and one-way analysis of variance (ANOVA). For all the statistical tests, $\mathrm{p}<0.05$ was considered statistically significant.

\section{RESULTS}

\section{Probing Pocket Depth}

The mean probing depth at baseline, 1 month, 3 months and 6 months post-surgery was $8.38 \pm 2.257 \mathrm{~mm}, 3.06 \pm 0.853 \mathrm{~mm}$, $2.70 \pm 0.656 \mathrm{~mm}, 2.61 \pm 0.523 \mathrm{~mm}$, respectively. The reduction in probing depth was continued from baseline to 6 months after the surgery. The difference in mean probing pocket depth from baseline to 1 month, 3 months and 6 months was statistically significant as shown in Table 1

\section{Clinical Attachment Level}

There was an increase in the clinical attachment level after surgical therapy. At baseline the mean clinical attachment was $9.56 \pm 2.834 \mathrm{~mm}$, while at 1 month, 3 months and 6 months post-surgery was $5.17 \pm 1.939 \mathrm{~mm}, 4.88 \pm 1.735 \mathrm{~mm}$, $4.81 \pm 1.682 \mathrm{~mm}$, respectively. The difference in mean clinical attachment level from baseline to 1 month, 3 months and 6 months post-surgery was statistically significant (Table 1)

\section{Gingival Recession Depth (Measured from CEJ to Gingival Margin)}

The mean gingival recession depth at baseline was $1.16 \pm$ $1.264 \mathrm{~mm}$. 1month, 3 months and 6 months post-surgery the recession depth was increased to $2.11 \pm 1.483 \mathrm{~mm}, 2.18 \pm$ $1.472 \mathrm{~mm}, 2.20 \pm 1.493 \mathrm{~mm}$, respectively. The difference in mean gingival recession depth from baseline to 1 month, 3 months, 6 months was statistically significant as shown in Table 1.

\section{The Amount of Bone Loss at Surgical Site (Measured from CEJ to Crest of the Alveolar Bone)}

At baseline the mean amount of bone loss in 120 surgical sites was $6.173 \pm 2.5029 \mathrm{~mm}$. Among 120 surgical sites, 17 sites $(14.2 \%)$ had $<3 \mathrm{~mm}$ of bone loss, 38 sites (31.7\%) had 3-5 mm of bone loss, 54 sites (45\%) had 5-10 mm of bone loss, 11 sites (9.2\%) had > $10 \mathrm{~mm}$ of bone loss. (Table 2 ).

\section{Correlation of Gingival Recession Depth with the Amount of Bone Loss at the Surgical Site}

17 sites with $<3 \mathrm{~mm}$ of bone loss showed no difference in the mean gingival recession from baseline $(0.71 \pm 0.470 \mathrm{~mm})$ to 1 month, 3 months, 6 months after the flap surgery. The mean gingival recession was increased from baseline $(0.89 \mathrm{~mm} \pm$ $0.924 \mathrm{~mm})$ to 6 months $(1.47 \mathrm{~mm} \pm 0.979)$ post-surgery in 38 sites with the bone loss of 3-5 mm. The difference was statistically significant $(\mathrm{p}<0.05) .54$ sites with the bone loss of $5-10 \mathrm{~mm}$ had increase in mean gingival recession from baseline $(1.46 \mathrm{~mm} \pm 1.58 \mathrm{~mm})$ to 1 month $(2.80 \mathrm{~mm} \pm 1.54$ $\mathrm{m}), 3$ months $(2.93 \mathrm{~mm} \pm 1.465 \mathrm{~mm})$ and 6 months $(2.98 \mathrm{~mm}$ $\pm 1.49 \mathrm{~mm}$ ) after the surgery. The difference was statistically significant $(\mathrm{p}<0.001)$.

There was increase in the mean gingival recession from baseline $(1.27 \pm 1.009)$, to 1 month $(3.09 \mathrm{~mm} \pm 1.044 \mathrm{~mm}), 3$ months $(3.27 \mathrm{~mm} \pm 0.786 \mathrm{~mm}), 6$ months $(3.18 \mathrm{~mm} \pm 0.751$ $\mathrm{mm}$ ) at 11 sites with $>10 \mathrm{~mm}$ of bone loss $(\mathrm{p}<0.001)$. (Table 3).

The pair wise comparison between the visits showed statistically significant increase in recession depth from baseline to 1 month, 3 months and 6 months post-surgery in sites with $>3 \mathrm{~mm}$ of bone loss. (Table 4 ). 
Prediction Chart for the Post -operative Gingival Recession

Table 5 shows the predicted depth of postsurgical recession for various PPD, CAL and radiographic bone loss at the surgical site.

\begin{tabular}{|c|c|c|c|c|c|c|c|c|c|c|c|c|}
\hline & $\sum_{\bar{n}}^{\frac{\pi}{5}}$ & $z$ & 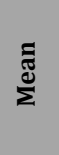 & के & 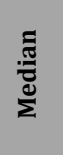 & $\dot{\Xi}$ & $\sum^{\dot{x}}$ & $\ddot{\sigma}$ & $\approx$ & $\ddot{\sigma}$ & 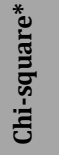 & \\
\hline \multirow{4}{*}{ 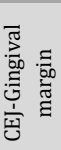 } & Baseline & 120 & 1.16 & 1.264 & 1.00 & 0 & 4 & 0.00 & 1.00 & 2.00 & \multirow{4}{*}{$\begin{array}{l}\text { 岁 } \\
\text { ఫे } \\
\dot{y}\end{array}$} & \multirow{4}{*}{$\begin{array}{l}\vec{\circ} \\
\dot{0} \\
\dot{v}\end{array}$} \\
\hline & Month 1 & 120 & 2.11 & 1.483 & 2.00 & 0 & 6 & 1.00 & 2.00 & 3.00 & & \\
\hline & Month 3 & 120 & 2.18 & 1.472 & 2.00 & 0 & 6 & 1.00 & 2.00 & 3.00 & & \\
\hline & Month 6 & 120 & 2.20 & 1.493 & 2.00 & 0 & 6 & 1.00 & 2.00 & 3.00 & & \\
\hline \multirow{4}{*}{ 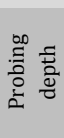 } & Baseline & 120 & 8.38 & 2.257 & 8.00 & 5 & 13 & 6.00 & 8.00 & 10.00 & \multirow{4}{*}{$\begin{array}{l}\vec{\infty} \\
\stackrel{\infty}{+} \\
\dot{0}\end{array}$} & \multirow{4}{*}{$\begin{array}{l}\tilde{8} \\
\dot{0} \\
\text { v }\end{array}$} \\
\hline & Month 1 & 120 & 3.06 & 0.853 & 3.00 & 2 & 5 & 2.00 & 3.00 & 4.00 & & \\
\hline & Month 3 & 120 & 2.70 & 0.656 & 3.00 & 2 & 4 & 2.00 & 3.00 & 3.00 & & \\
\hline & Month 6 & 120 & 2.61 & 0.523 & 3.00 & 2 & 4 & 2.00 & 3.00 & 3.00 & & \\
\hline \multirow{4}{*}{ త్త్ర } & Baseline & 120 & 9.56 & 2.834 & 9.50 & 6 & 16 & 6.00 & 8.00 & 10.00 & \multirow{4}{*}{ 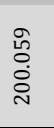 } & \multirow{4}{*}{$\begin{array}{l}-\dot{8} \\
\dot{0} \\
\mathrm{v}\end{array}$} \\
\hline & Month 1 & 120 & 5.17 & 1.939 & 5.00 & 2 & 10 & 2.00 & 3.00 & 4.00 & & \\
\hline & Month 3 & 120 & 4.88 & 1.735 & 5.00 & 2 & 9 & 2.00 & 3.00 & 3.00 & & \\
\hline & Month 6 & 120 & 4.81 & 1.682 & 5.00 & 2 & 9 & 2.00 & 3.00 & 3.00 & & \\
\hline \multicolumn{13}{|c|}{ Table 1. Clinical Parameters Recorded at Different Time Points } \\
\hline \multicolumn{13}{|c|}{$\begin{array}{l}\text { CEJ: Cemento-enamel junction, CAL: Clinical attachment level, N: Number, SD: } \\
\text { Standard deviation }\end{array}$} \\
\hline
\end{tabular}

\begin{tabular}{|cccc|}
\hline Visit & Bone loss & Frequency & Percent \\
& $<3 \mathrm{~mm}$ & 17 & 14.2 \\
Baseline & $3-5 \mathrm{~mm}$ & 38 & 31.7 \\
& $5-10 \mathrm{~mm}$ & 54 & 45.0 \\
& $>10 \mathrm{~mm}$ & 11 & 9.2 \\
& Total & 120 & 100.0 \\
\hline \multicolumn{3}{|c|}{ Table 2. The Amount of Bone Loss at Surgical Site } \\
(Measured from CEJ to crest of the alveolar bone)
\end{tabular}

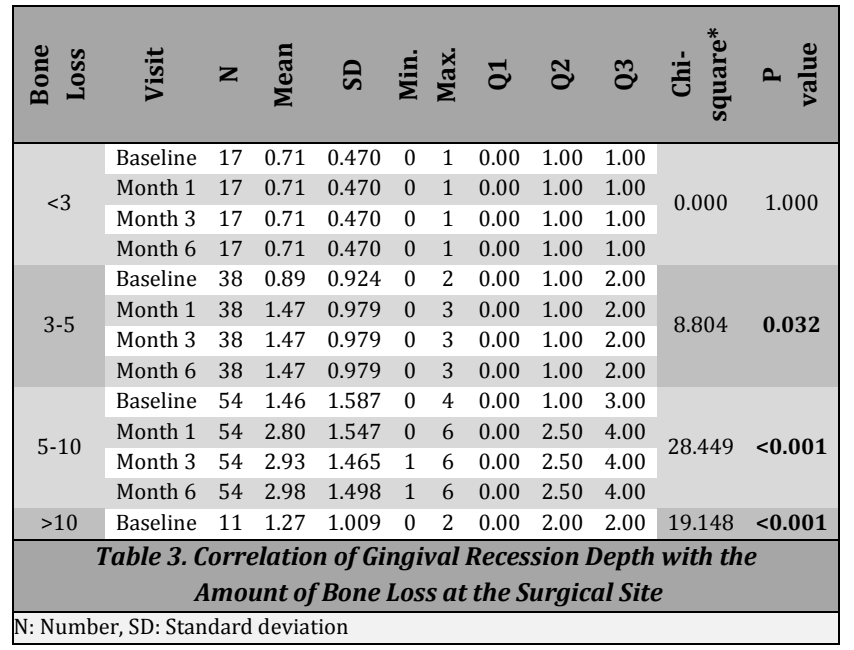

\begin{tabular}{|c|c|c|c|c|c|c|}
\hline $\begin{array}{l}\tilde{\partial} \\
\stackrel{]}{0} \\
\vdots \\
0\end{array}$ & 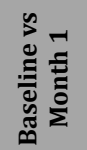 & 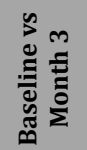 & 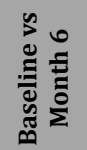 & 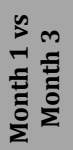 & 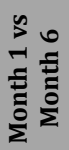 & 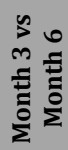 \\
\hline$<3 \mathrm{~mm}$ & 1.000 & 1.000 & 1.000 & 1.000 & 1.000 & 1.000 \\
\hline 3-5 mm & 0.016 & 0.016 & 0.016 & 1.000 & 1.000 & 1.000 \\
\hline $5-10 \mathrm{~mm}$ & $<0.001$ & $<0.001$ & $<0.001$ & 0.733 & 0.612 & 0.877 \\
\hline$>10 \mathrm{~mm}$ & 0.001 & 0.001 & 0.001 & 0.660 & 0.748 & 0.797 \\
\hline
\end{tabular}

\begin{tabular}{|cccc|}
\hline Bone Loss & PPD & CAL & Recession \\
$<3 \mathrm{~mm}$ & $6 \mathrm{~mm}$ & $6-7 \mathrm{~mm}$ & $<1 \mathrm{~mm}$ \\
$3-5 \mathrm{~mm}$ & $6-8 \mathrm{~mm}$ & $6-10 \mathrm{~mm}$ & $1-2 \mathrm{~mm}$ \\
$5-10 \mathrm{~mm}$ & $8-10 \mathrm{~mm}$ & $10-12 \mathrm{~mm}$ & $2-3 \mathrm{~mm}$ \\
$>10 \mathrm{~mm}$ & $>12 \mathrm{~mm}$ & $12-14 \mathrm{~mm}$ & $>3 \mathrm{~mm}$ \\
\hline Table 5. Prediction Chart for the Post & -operative Gingival Recession \\
\hline
\end{tabular}

\section{DISCUSSION}

Many studies have come to the conclusion that periodontal surgical procedures resulted in postoperative recession. ${ }^{9,11,12}$ Isidor et al. in a study compared the clinical results of root planning, reverse bevelled flap without osseous surgery and modified Widman flap. It showed that surgical procedures resulted in statistically significant reduction in clinical attachment level gain and probing depth at 3- and 6-months examination. In spite of that, the surgical procedures resulted in a significant recession compared to baseline. $(2.2 \mathrm{~mm}$ for modified Widman flap and $1.8 \mathrm{~mm}$ for root planning). ${ }^{11}$

In a recent study, Becker et al. estimated the clinical outcomes of scaling, osseous surgery and modified Widman procedures, found an improvement in clinical attachment level and a significant reduction in probing depth, but with a significant post-surgical gingival recession after 5 years (mean of $1.28 \mathrm{~mm}, 2.18 \mathrm{~mm}, 1.70 \mathrm{~mm}$ ). ${ }^{9}$ Kaldahl et al. also reported that statistically significant recession occurs for several surgical techniques such as flap debridement, osseous surgery and root planning (mean of $1.2 \mathrm{~mm}, 1.5 \mathrm{~mm}$ and $0.8 \mathrm{~mm}$, respectively). ${ }^{12}$

The clinical outcome of present study coincided with the results of preceding studies that flap surgery induced considerable improvement in probing depth and clinical attachment level, but significant gingival recession at 1 month, 3 month and 6 months after examination.

The postoperative recession was found to correspond with initial probing depth; i.e., it was more pronounced at sites with deeper periodontal pockets. Various explanations have been suggested for postoperative recession including thin gingival tissue with limited blood supply, lack of bone support for the flap and postoperative shrinkage of the flap. ${ }^{9,10}$

According to our knowledge this is a novel study conducted to correlate the postoperative recession with the amount of bone loss at the surgical site. The changes in the recession of gingival margin were recorded from baseline to six months after therapy as studies have shown that the major changes resulting from active therapy occur within the first six months following therapy i.e., the healing phase. ${ }^{13}$ In another study, following flap surgery, the apical shift of gingival margin position was appreciated in $29 \%$ of sites from baseline to six months post treatment. The apical shift was highly significant $(\mathrm{P}<0.001) .{ }^{14}$

Gingival recession was also found to correlate with age and bone loss. A statistically significant difference was found in the correlation between bone loss and gingival recession when comparing dehiscence/fenestration sites and nondehiscence / fenestration sites. Lost studied a correlation between gingival recession and alveolar bone loss. ${ }^{15}$ Periodontal flap surgeries of 50 recessions areas which included 113 affected teeth were done on 27 patients with an average age of 25.6 years. They assessed dehiscence defects and gingival recession of 113 teeth in vivo and found the average bone dehiscence depth to be $5.4 \mathrm{~mm}$ and average soft tissue recession depth of $2.7 \mathrm{~mm} .{ }^{16}$ In contrast, results of the present study showed that sites with the bone loss of 5-10 $\mathrm{mm}$ had mean gingival recession of $1.46 \mathrm{~mm}$ at baseline which was increased to $2.93 \mathrm{~mm}$ at 6 months after the flap surgery. The result from this study, that is, increased bone 
loss corresponds with increased recession is in agreement with Lost's study, which found gingival recession to correlate, on average, to underlying buccal bone loss. But literature lacks studies that could help to compare the results of the present study.

This study indicates that the amount of bone loss at the surgical site can be a strong predictor for the postoperative recession depth following flap surgery. It is important for a clinician to predict the post-operative recession that can occur for the particular amount of bone loss at the surgical site following periodontal therapy. This knowledge helps the clinician to convey the realistic expectations about surgical outcome to the patients in day-to-day practice.

\section{CONCLUSIONS}

Clinical inference of this study includes the validations that gingival recession following flap surgery correlates with the bone loss at the surgical site and sites with greater bone loss showed increased postoperative recession.

Data sharing statement provided by the authors is available with the full text of this article at jemds.com.

Financial or other competing interests: None.

Disclosure forms provided by the authors are available with the full text of this article at jemds.com.

\section{REFERENCES}

[1] Camargo PM, Melnick PR, Kenney EB. The use of free gingival grafts for aesthetic purposes. Periodontol 2000 2001;27:72-96.

[2] Wennström JL, Zucchelli G. Increased gingival dimensions. A significant factor for successful outcome of root coverage procedures? A 2-year prospective clinical study. J Clin Periodontol 1996;23(8):770-7.

[3] Kleber BM, Schenk HJ. Etiology of gingival recessions. Dtsch Zahnarztl Z 1989;44(11):845-8.
[4] Khosya B, Devaraj CG. Etiology and severity of different grades of gingival recession in adult population. Natl J Med Res 2014;4(3):189-92.

[5] Kundapur PP, Bhat KM, Bhat GS. Association of trauma from occlusion with localized gingival recession in mandibular anterior teeth. Dent Res J 2009;6(2):71-4.

[6] Badersten A, Nilveus R, Egelberg J. Effect of nonsurgical periodontal therapy. II. Severely advanced periodontitis. J Clin Periodontol 1984;11(1):63-76.

[7] Isidor F, Karring T, Attstrom R. The effect of root planing as compared to that of surgical treatment. J Clin Periodontol 1984;11(10):669-81.

[8] Palcanis KG. Surgical pocket therapy. Ann Periodontol 1996;1(1):589-617.

[9] Becker W, Becker BE, Caffesse R, et al. A longitudinal study comparing scaling, osseous surgery and modified Widman procedures: results after 5 years. J Periodontol 2001;72(12):1675-84.

[10] Hall WB. Gingival augmentation/ mucogingival surgery. In: Proceedings of the World Workshop in Clinical Periodontics. Chicago: American Academy of Periodontology 1989:VII/I-VII/21.

[11] Isidor F, Karring T, Attstron R. The effect of root planing as compared to that of surgical treatment. J Clin Periodontol 1984;11(10):669-81.

[12] Kaldahl WB, KalKwarf KL, Patil KD, et al. Long-term evaluation of periodontal therapy: I. Response to 4 therapeutic modalities. J Periodontol 1996;67(2):93-102.

[13] Lindhe J, Socransky SS, Nyman S, et al. Dimensional alterations of the periodontal tissues following therapy. Int J Periodontics Restorative Dent 1987;7(2):9-21.

[14] Gupta I, Vandana KL. Alterations of the marginal soft tissue (gingival margin) following periodontal therapy: a clinical study. J Indian Soc Periodontol 2009;13(2):86-9.

[15] Sather C. Factors affecting gingival recession in the esthetic zone: a human cadaver study. [dissertation] Loma Linda University 2014:1-4.

[16] Lost C. Depth of alveolar bone dehiscences in relation to tissue recessions. J Clin Periodontol 1984;11(9):583-9. 